\title{
Strong Current Events Related to a Subtropical Front in the Northeast Atlantic ${ }^{\ddagger}$
}

\author{
G. SIEDLER AND W. ZENK \\ Institut für Meereskunde, Kiel University, F.R. Germany \\ W. J. EMERY \\ University of British Columbia, Vancouver, B.C., Canada
}

(Manuscript received 10 September 1984, in final form 20 February 1985)

ABSTRACT

\begin{abstract}
Long-term temperature and current-meter records from moorings in the northern Canary Basin display strong current events with time scales between one and three months and large vertical scales of several thousand meters. The data are compared to hydrographic surveys in the area that show a meandering subtropical front. The strong current events are found to be related to the passage of the front through the mooring positions. An analysis of composite time series, for selected depths, indicates cases of westward and of eastward propagation of frontal meanders. The frontal pattern is also found in geopotential anomalies inferred from historical XBT data sets, suggesting that the front is a persistent feature of the density field. In two cases strong current events appear to be related to a Mediterranean Water lens.
\end{abstract}

\section{Introduction}

Strong current events of several months' duration were found in long-term current meter records from the Canary Basin, between the Azores and the Canary Islands, where the bottom depth is close to $5300 \mathrm{~m}$. As will be shown in this study the majority of these events can be attributed to the passage of a meandering thermohaline front. At this latitude of the eastern North Atlantic, such oceanic fronts are to be expected. A balance of the gradients of heat and/or salt advection and the gradients of the flux divergence of heat and/ or salt is required for quasi-stationary fronts to exist (Roden, 1972). In the area under consideration surface heat flux changes from positive (oceanic gain) to negative when proceeding to the north (Bunker, 1976), surface water flux changes from negative to positive (Schmitt, personal communication, 1983), and a maximum in the wind stress curl (Hellerman and Rosenstein, 1983) will result in an Ekman flow convergence. Conditions are thus favorable for the existence of oceanic fronts. Once a front has been formed, an alongfront baroclinic current will exist unless the horizontal temperature gradient is balanced by the salinity gradient with respect to density.

The current band related to the front to be discussed is part of a mean eastward current system located south and southeast of the Azores (Stramma, 1984; Maillard, 1984; Pollard and $\mathrm{Pu}, 1985$ ). A description

$\ddagger$ Contribution Number 5758 of the Woods Hole Oceanographic Institution. of the front was given earlier by Käse and Siedler (1982), based on hydrographic data that had been obtained on F.S. Meteor and F.S. Poseidon in spring 1982 and satellite drifter data. A similar front had been found farther to the west in summer 1981 (Gould, 1985) which is probably connected to the front discussed here.

\section{The data sets}

Three sets of data, covering increasing lengths of time, will be used for this study:

1) Hydrographic data from cruise Number 60 , legs 3 and 4, of F.S. Meteor, February-April 1982.

2) Moored temperature/pressure/current meter data for the period January 1980-October 1983.

3) Expendable Bathythermograph (XBT) data from 1966 to 1979.

In addition, a few CTD profiles will be used from F.S. Poseidon cruise Number 86/2, April 1982 (Käse and Rathlev, 1982). The cruise tracks and CTD stations of F.S. Meteor Number 60 are presented in Fig. 1. A boxlike pattern with XBT stations was selected after a front had been identified in the section leading from the Canary Islands to the Azores, which is seen cutting through the center of the box oriented southeast to northwest.

The positions of the moorings are also shown in Fig. 1. Mooring 276 (named 264 for the earlier part of the record) has a nominal position at $33^{\circ} \mathrm{N}, 22^{\circ} \mathrm{W}$, the earlier NEADS Site 1 (Dickson, 1983). The records being considered here cover five consecutive 


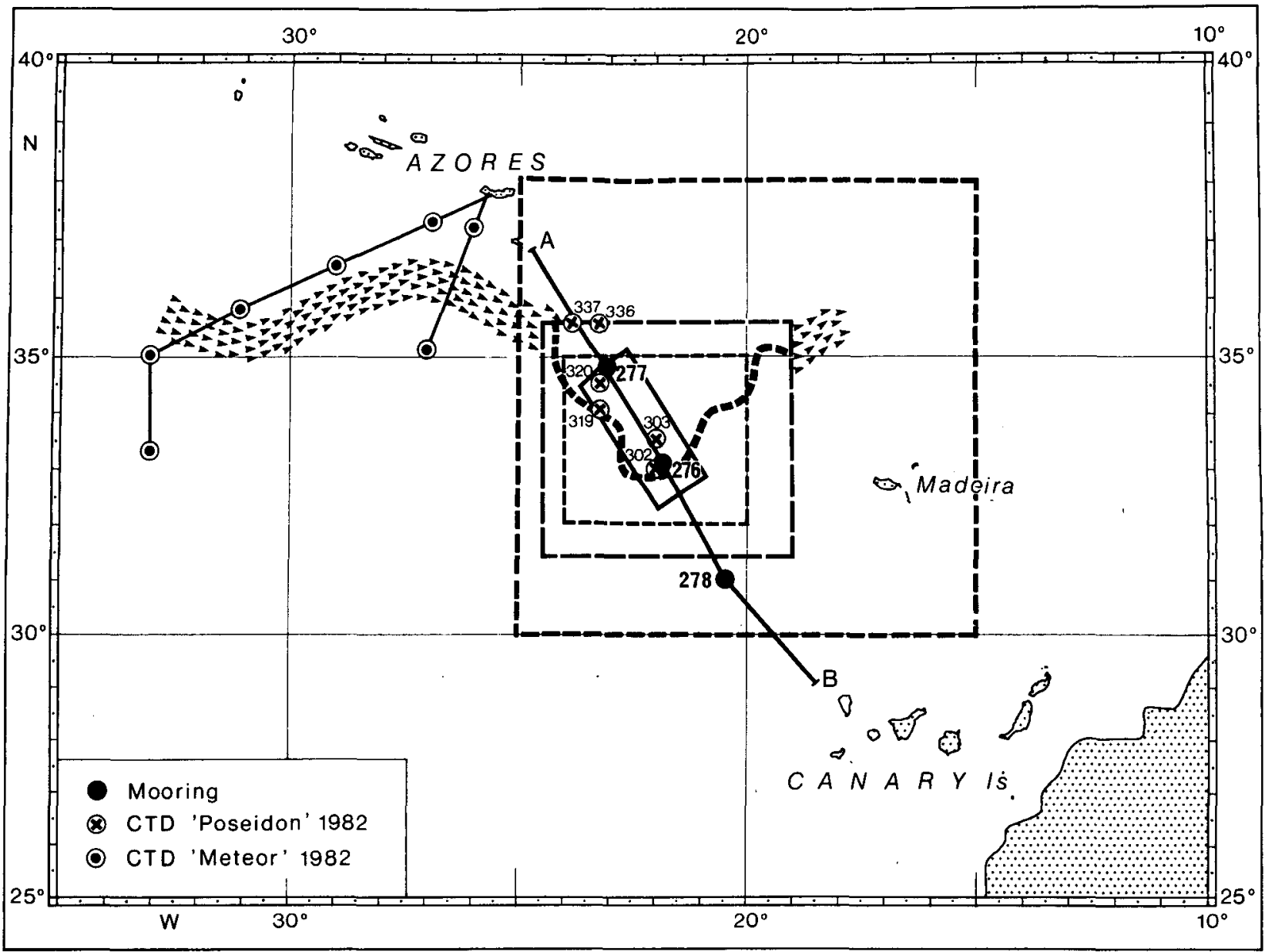

Fig. 1. Selected tracks (solid lines) of Meteor cruise Number 60 and Poseidon cruise Number 86 in spring 1982. Positions of longterm moorings are given by full circles. The position of a subtropical front (arrows) was reproduced from Käse and Siedler (1982), with a more precise location given in the intermediate-size box deduced from Käse et al. (1985). Dashed line boxes: Small box refers to Fig. 3 , intermediate box indicates area of Poseidon observations including the frontal meander, large box refers to Figs. 14 and 15 . XBT section $\mathrm{AB}$ is shown in Fig. 2.

periods, with the moorings having been replaced four times:

(i) 1 April 1980-17 October 1980 (Number 264-1)

(ii) 17 October 1980-27 July 1981 (Number 276-1)

(iii) 27 July 1981-2 March 1982 (Number 276-2)

(iv) 5 March 1982-17 April 1983 (Number 276-3)

(v) 22 April 1983-15 October 1983 (Number 276-4)

Data from mooring 277 (earlier NEADS Site 11, nominal position $34^{\circ} 45^{\prime} \mathrm{N}, 23^{\circ} 00^{\prime} \mathrm{W}$ ) to the northwest of mooring 276 were obtained for the following periods:

(iii) 29 July 1981-7 March 1982 (Number 277-2)

(iv) 7 March 1982-30 April 1983 (Number 277-3)

Mooring 278 (earlier NEADS Site 12, nominal position $\left.31^{\circ} \mathrm{N}, 20.30^{\prime} \mathrm{W}\right)$ to the southeast of mooring 276 provided data for the following period: (iii) 25 July 1981-1 March 1982 (Number 278-2).

Details of the mooring data can be found in data reports (Müller, 1981, 1984; Müller and Zenk, 1983).

The historical XBT data set was taken from the combined files of the U.S. National Oceanographic Data Center (NODC) and the U.S. Navy Fleet Numerical Oceanographic Center (FNOC) as described by Emery (1983).

\section{The front in spring 1982}

The temperature distribution along the Canary Islands/Azores section between points $A$ and $B$ (see Fig. 1) is presented in Fig. 2. The resulting density is calculated by using mean temperature/salinity relationships for this area (Emery and Dewar, 1982; Siedler and Stramma, 1983). Information on the 


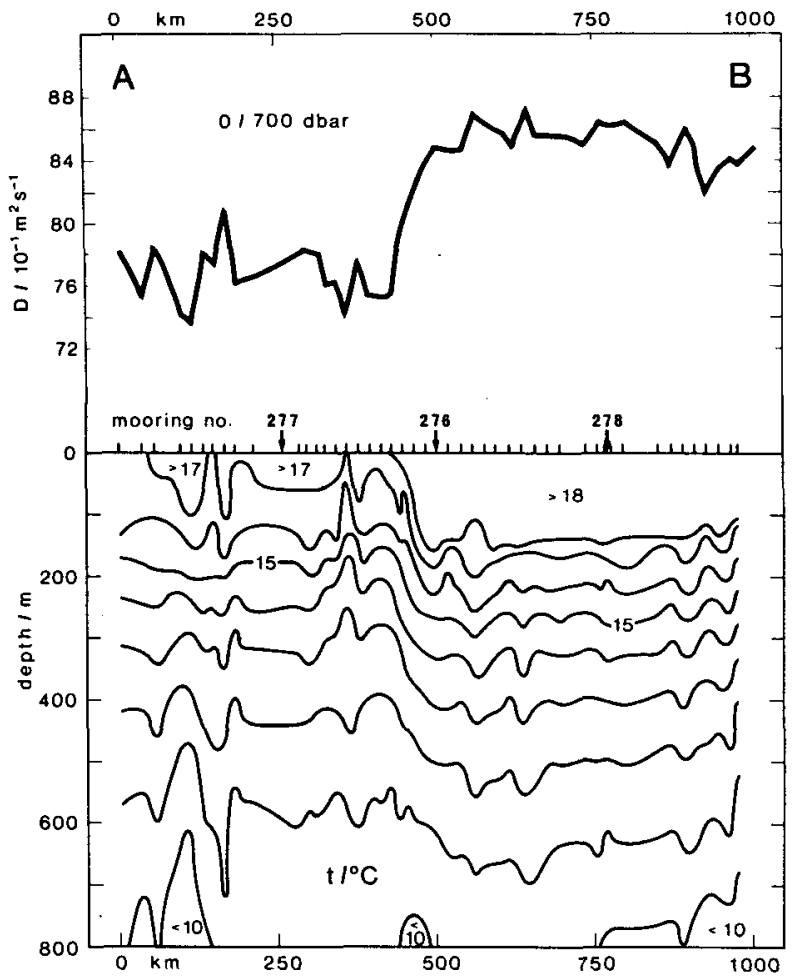

FIG. 2. Temperature distribution (below) from XBT observations along section A-B in Fig. 1 and corresponding geopotential anomaly relative to $700 \mathrm{db}$ (above) obtained from the temperature data and mean temperature-salinity relationships.

applicability and estimated errors can be found in the given literature. The geopotential anomaly (dynamic height) relative to $700 \mathrm{db}$ obtained from this density distribution changes by $1 \mathrm{~m}^{2} \mathrm{~s}^{-1}$ (10 dynamic centimeters) over a distance of approximately $70 \mathrm{~km}$ at the thermal front that can be seen in the section. It was shown by Käse and Siedler (1982) that similar thermal fronts can be identified at other positions south and southeast of the Azores (see Fig. 1), and that streamline patterns of geostrophic currents, obtained from CTD data, suggest the presence of mesoscale eddies on both sides of the front. The existence of a continuous temperature gradient pattern was confirmed by the inspection of infrared satellite photographs.

We will be concerned here mainly with the area close to moorings 276 and 277 , i.e., the area of the inner box indicated in Fig. 1. An objective analysis of the XBT data, converted to geopotential anomalies, is presented in Fig. 3. A current band can be seen, cutting through the northwestern corner of the box with southward flow, and then crossing the southern part of the box with eastward flow. At the time of this survey in March 1982, mooring 277 was east of the southward flow, and mooring 276 was in the eastward flow.
To illustrate the thermohaline character of the front, profiles are presented in Fig. 4 from CTD station pair 302 and 303 obtained in early April 1982 just south and north of the maximum geostrophic current near mooring 276 (see Figs. 1 and 3). The vertical changes in potential density anomaly between the two stations, $\left[\sigma_{\theta}\left(S_{303}, t_{303}\right)-\sigma_{\theta}\left(S_{302}, t_{302}\right)\right]$ due to changing salinity $S$ and temperature $t$, are compared to density changes $\left[\sigma_{\theta}\left(S_{303}, t_{302}\right)-\sigma_{\theta}\left(S_{302}, t_{302}\right)\right]$ due to salinity variations alone and to density changes $\left[\sigma_{\theta}\left(S_{302}, t_{303}\right)-\sigma_{\theta}\left(S_{302}, t_{302}\right)\right]$ due to temperature variations alone. While major density changes due to temperature and salinity variations compensate each other with respect to density to a large extent at Mediterranean Water levels between 900 and 1200 $\mathrm{db}$, this is not the case in the thermocline front between 100 and $400 \mathrm{db}$. The density increases due to the higher salinities are only partly compensated by lower temperatures. The front discussed here is a thermohaline front and also a density front with corresponding baroclinic currents.

\section{Composite time series of mooring data}

Figure 5 presents current vector time series of moorings 276 (264) for various depth levels. Similar series from moorings 277 and 278 are given in Fig. 6. Data were low-pass filtered with a cutoff period of about 24 hours, and daily-mean vectors from the

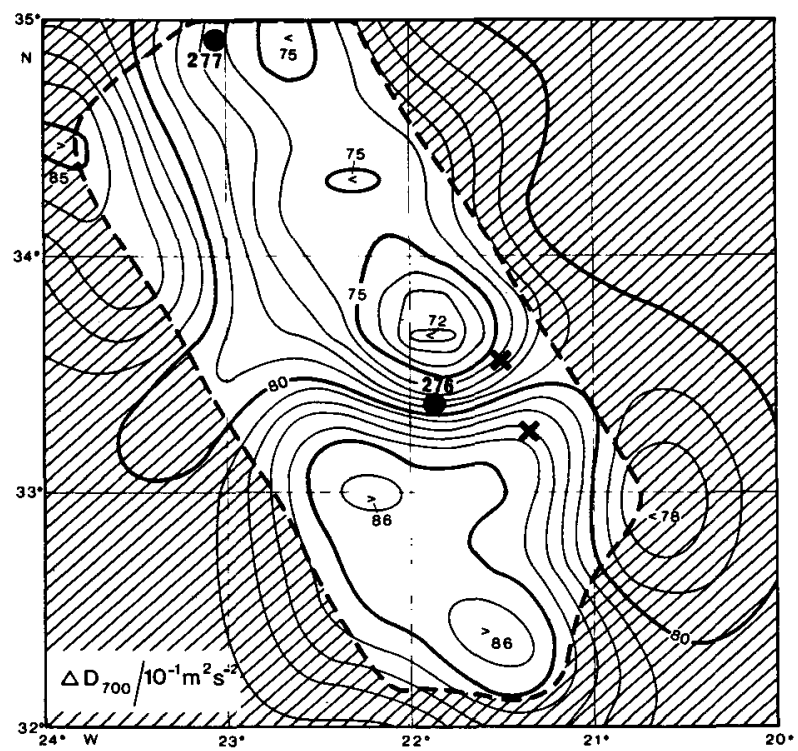

FIG. 3. Geopotential anomaly relative to $700 \mathrm{db}$ for small box given in Fig. 1, calculated using objective analysis. In the dotted area the estimated error variance exceeds $40 \%$ of the variance of the true geopotential anomaly field. A Gaussian isotropic covariance function with a correlation scale of $30 \mathrm{~km}$ was chosen to smooth out variability on smaller scales. Full circles indicate mooring positions, crosses represent XBT drops 131 (south) and 144 (north). 

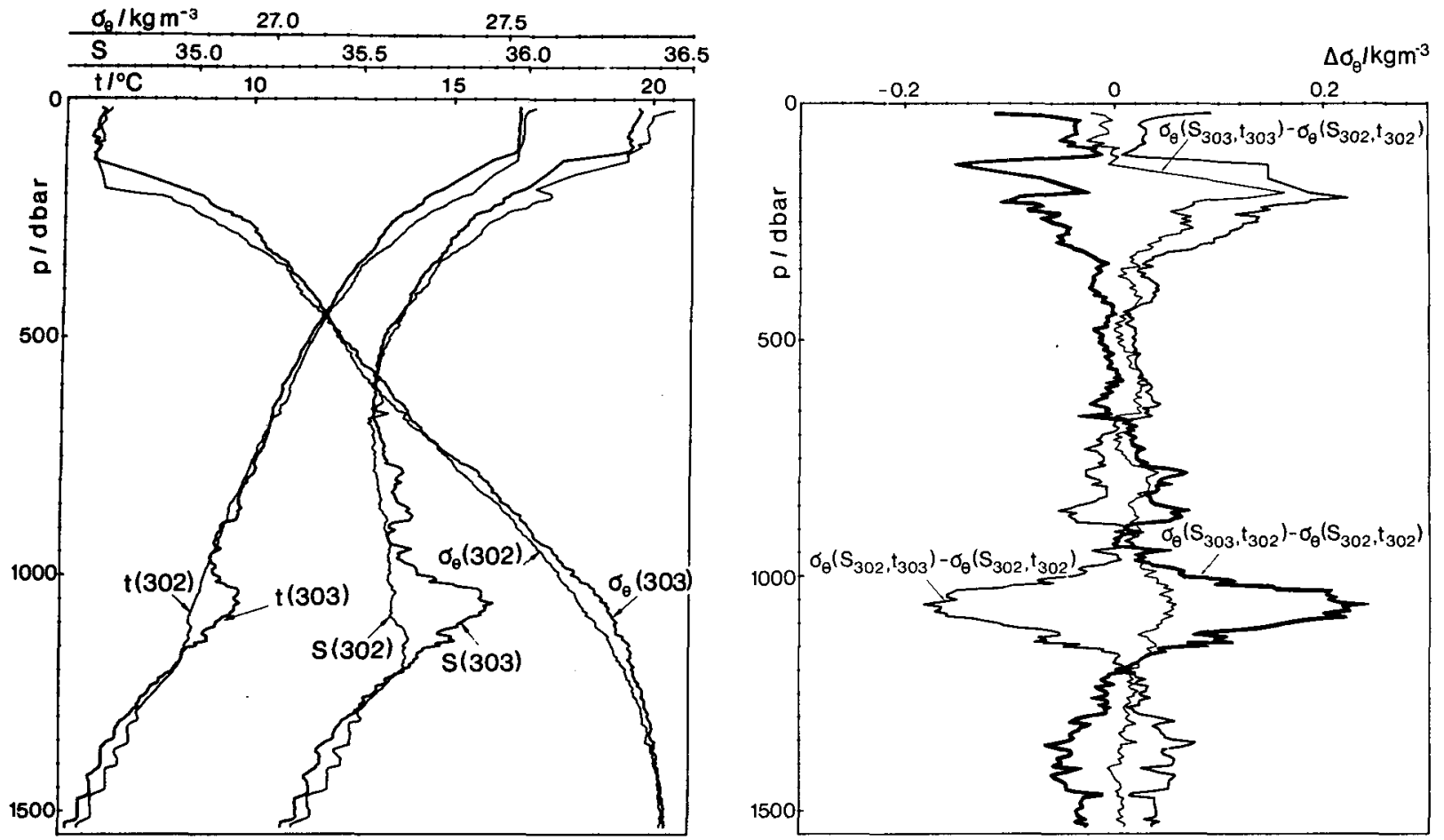

FIG. 4. Left: Temperature $t$, salinity $S$ and potential density anomaly $\sigma_{\theta}$ at stations 302 and 303 (see Fig. 1). Right: Horizontal difference of potential density anomaly between these stations $\left[\sigma_{\theta}\left(S_{303}, t_{303}\right)-\sigma_{\theta}\left(S_{302}, t_{302}\right)\right]$, difference due to salinity change alone $\left[\sigma_{\theta}\left(S_{303}, t_{302}\right)-\sigma_{\theta}\left(S_{302}, t_{302}\right)\right]$ and difference due to temperature change alone $\left[\sigma_{\theta}\left(S_{302}, t_{303}\right)-\sigma_{\theta}\left(S_{302}, t_{302}\right)\right]$.

low-passed series were plotted, thus eliminating tidal and inertial wave signals. No speed data were available in one case in Fig. 5 and three cases in Fig. 6. Artificial constant speeds (given in the figure) were used for those series in order to provide information on directional changes.

Immediately apparent from the plots in Fig. 5 are strong current events, with durations between one and three months and maximum speeds up to about $30 \mathrm{~cm} \mathrm{~s}^{-1}$. The current direction during these events is predominantly along a north-south line, although care has to be taken in interpreting the vector time series plots where the eastward direction coincides with the time coordinate. Spectral analysis, however, confirms the dominance of the north-south over the east-west components on the corresponding time scales. Also easily seen in the vector time series is the strong correlation of the events over most of the water column. From June to August 1980 strong currents with similar directions are seen at all levels between $125 \mathrm{~m}$ and $4790 \mathrm{~m}$, i.e., close to the bottom. In another case, January to February 1982 at mooring 277 (shown in Fig. 6), a phase reversal is found below $3000 \mathrm{~m}$. Usually the speed decreases with depth, but on two occasions, June and August 1981 at mooring 276 (shown in Fig. 5), a speed maximum is apparent close to the $1000 \mathrm{~m}$ depth level in the Mediterranean Water. No significant $(95 \%)$ horizontal coherence was found when determining coherence spectra for overlapping time segments of time series at moorings 276 and 277.

Since the strong current events at each mooring extend over a wide depth range with slowly varying amplitude and phase, it is possible to generate composite time series by assembling parts of records that were obtained at different, although similar depths. Before presenting such composite current time series, however, we will discuss the use of corresponding temperature time series in such composite plots. Mooring motion cannot be neglected because strong current events with nearly constant phase of the currents in the water column are bound to produce large inclinations of the mooring line, increasing the depths of the meters. A composite pressure time series of the uppermost instruments in moorings 276 (264) is presented in Fig. 7, and a sudden increase of pressure can be seen on several occasions which can be related to current events in Fig. 5. Such large changes in depth level will lead to a decrease in the temperatures measured in the thermocline. For a study of temporal changes at fixed levels, the temperature time series have to be corrected for these changes in depth level. Temperature corrections were obtained by using the mean vertical temperature gradient during calm periods and the depth level changes given by the pressure records. The observed 

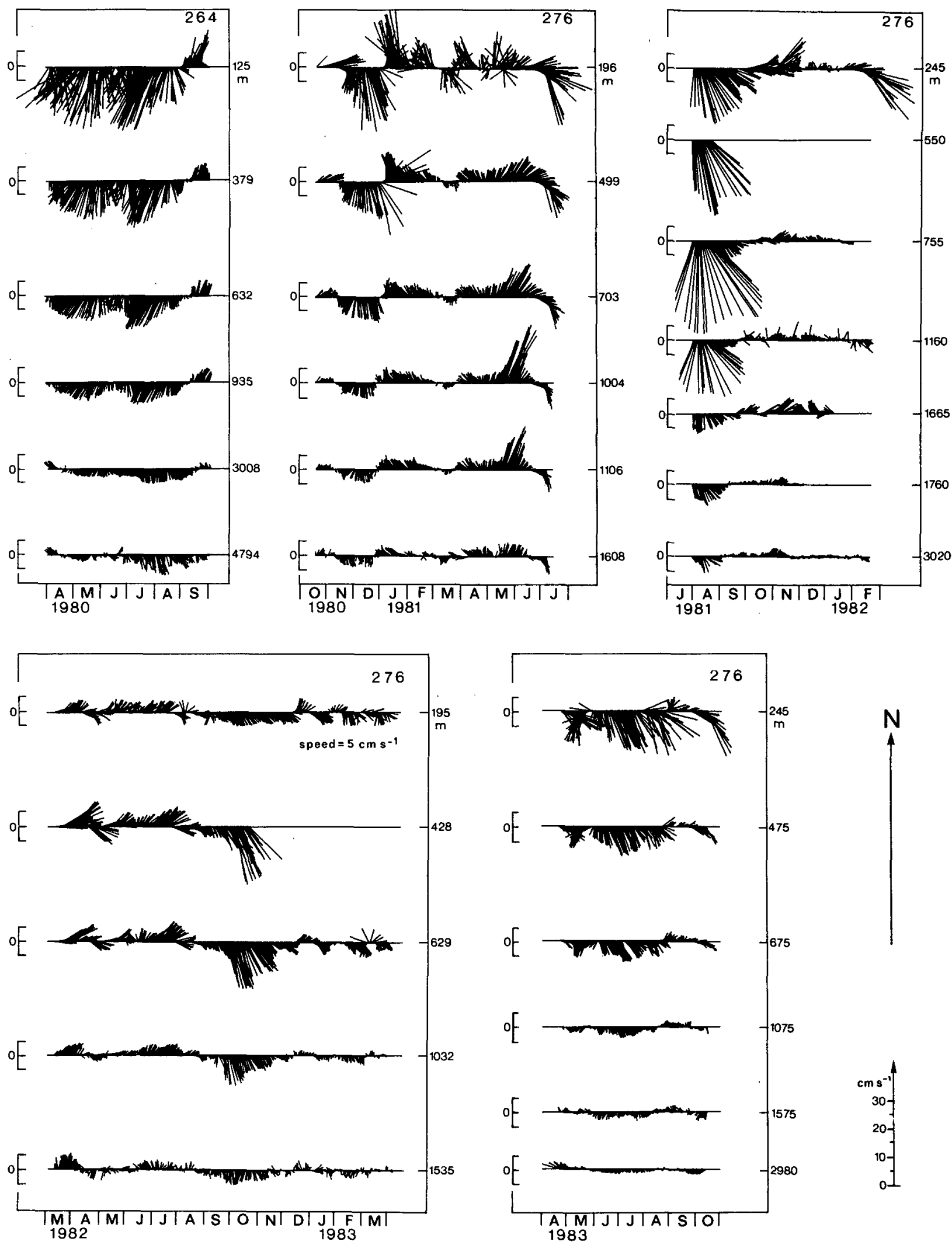

FIG. 5. Daily mean vector time series from mooring position 276 (264) given in Figs. 1 and 3. 

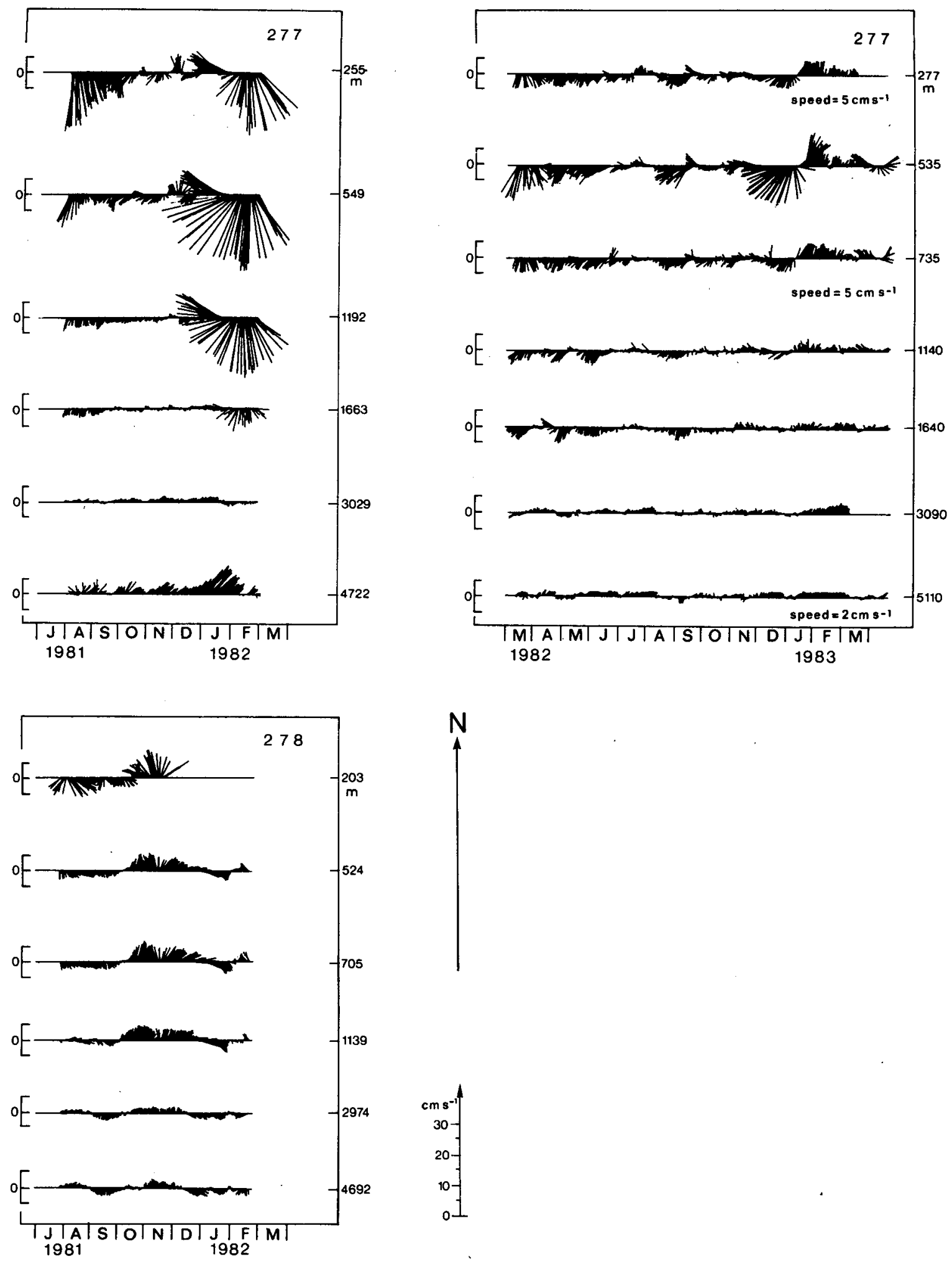

FIG. 6. Daily mean vector time series from mooring positions 277 (Figs. 1 and 3) and 278 (Fig. 1). 


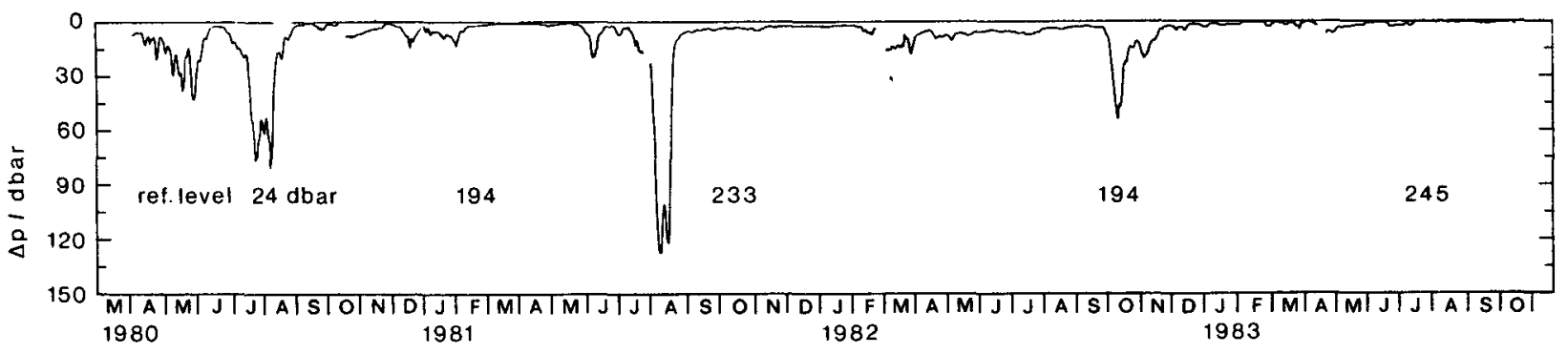

FIG. 7. Composite time series of pressure (approximate depth) changes at uppermost instruments in moorings 276 (264).

and corrected temperature series are presented in Fig. 8.

Taking into account the good vertical correlation of strong current events (at least down to levels below the Mediterranean Water core), and having corrected the temperatures in the main thermocline, we are now able to generate composite time series (Fig. 9) that summarize the events at moorings 276 (264). In two cases the near-surface currents and temperatures are not from the same depth levels because of current sensor failures, but meaningful results can nevertheless be obtained because of the slow vertical change in currents during events. Temporal changes in the upper thermocline are presented by composite vector time series of current records from similar depths and of corrected temperature records from the upper and central thermocline. Variations within the Mediterranean Water core are summarized by similar vector and temperature time series at the 1000 to $1100 \mathrm{~m}$ levels. However, temperatures cannot be corrected at these deeper levels by the above method because vertical profiles contain one or more highly variable temperature maxima at this depth range.

\section{Frontal meanders}

We now inspect the above composite time series, attempting to relate temporal changes at individual moorings to mesoscale features in this area. In the upper and central thermocline temperatures of Fig. 9, four strong temperature minima can be found, indicated by $\mathrm{D}, \mathrm{H}, \mathrm{J}$ and $\mathrm{L}$. In each of these cases, characteristic current direction variations appear to be associated with these temperature changes. Several other cases, although with less pronounced temperature minima, can be identified in cases $\mathrm{C}, \mathrm{E}$ and $\mathrm{K}$. In order to demonstrate the relation between directional and temperature variations, current time series were low-pass filtered with a frequency limit of $1 / 20$ $\mathrm{d}^{-1}$, and a median filter with a 15-day window was applied to the temperature time series which preserves the temperature minimum. Results are presented in Fig. 10. The periods of the five events C, D, H, J and $L$ defined in Fig. 9 are indicated by heavy lines. In cases $\mathrm{C}, \mathrm{D}, \mathrm{E}$ and $\mathrm{H}$ we find counterclockwise, in cases $J$ and $L$ clockwise directional changes at low temperatures.

The described sequence of current changes is probably caused by the passage of a current band associated with a frontal meander. Simultaneous hydrographic and moored current-meter observations (Käse and Siedler, 1982, Käse et al., 1985) showed this to be the case at least in March-April 1982. An essentially west-to-east oriented frontal current band was observed in the spring of 1982 and similarly on later cruises in spring and fall 1983 and fall 1984. With warm water in the south and cold water in the north, frontal meanders with cyclonic motion will have cold

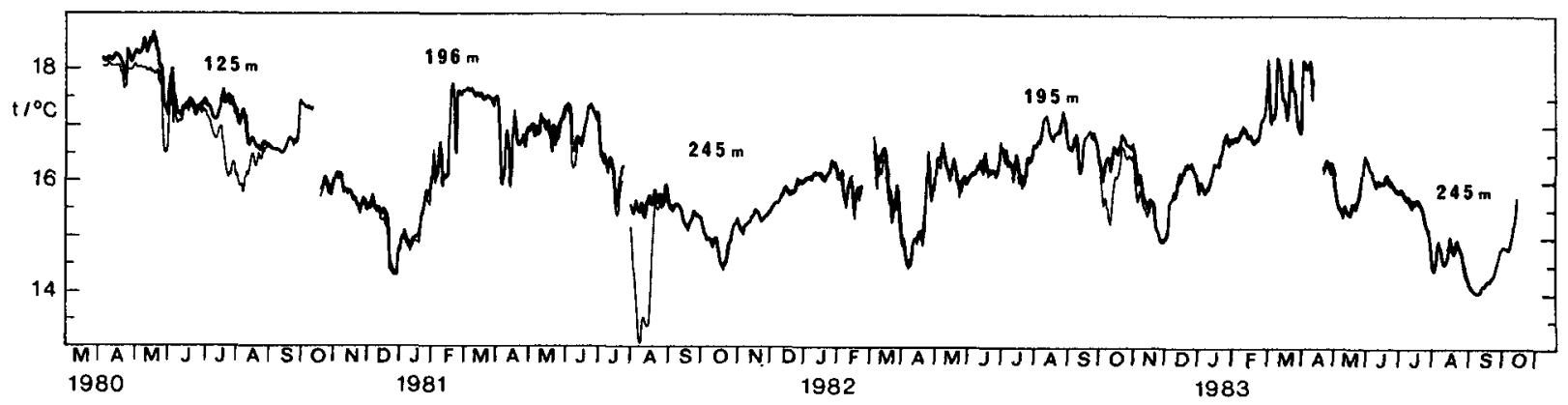

FIG. 8. Temperatures recorded by the uppermost instrument (thin line) in mooring 276 and temperatures corrected (heavy line) by using a mean vertical temperature gradient and observed pressure changes in Fig. 7. 


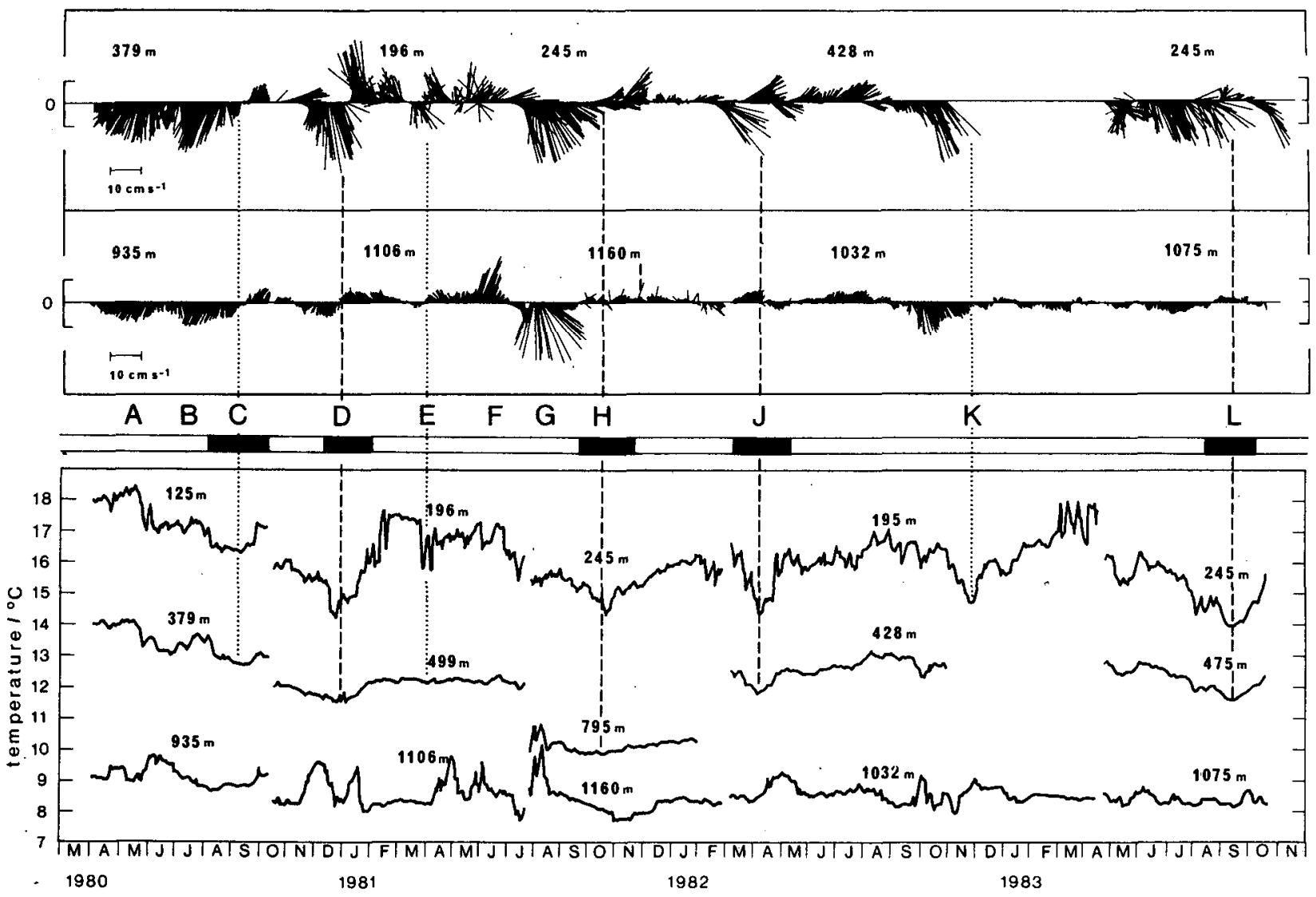

FIG. 9. Composite daily-mean time series from moorings 276 (264), from above: Current vectors in the upper thermocline, current vectors at the Mediterranean Water level, corrected temperature in the upper thermocline, corrected temperature in the central thermocline, observed temperature at the Mediterranean Water level. Capital letters and related dark lines indicate strong-current events.

water in their center while anticyclonic meanders will surround warm water. Temperature minima will then be related to the passage of cyclonic meanders.

A schematic diagram of the meander and the time series of current vectors and temperature is shown in Fig. 11. Also included on the right are diagrams of current direction versus temperature for the cases of westward (w) and eastward (e) phase propagation of the meanders. Both cases were found in Figs. 9 and 10. Apparently the large-scale flow field in some cases is strong enough to lead to an eastward phase propagation, thus overriding the westward propagation related to baroclinic Rossby waves. The westward propagation of event $\mathbf{H}$ was confirmed by satellite infrared radiometer observations of temperature surface front displacements in winter 1981/82 (G. Hardtke, personal communication, 1983).

Käse and Siedler (1982) noted the presence of mesoscale eddies on both sides of the frontal meander. The strongest currents, however, were confined to the frontal jet. In a more detailed correlation-scale analysis Käse et al. (1985) found that the dominant periods are 138 days for the north component and about half that number, 60 days, for the east component. They concluded that the longer period compares favorably with a first-mode westward propagating Rossby wave where most variability is expected in the meridional component. The shorter period was related to mesoscale eddies. Considering the fact, however, that the strongest currents are found close to the front itself, and that the autocorrelation function analysis of Käse et al. (1985) has some uncertainties, we do not confirm these conclusions here. Even a zonally propagating frontal jet alone will produce zonal and meridional currents at a fixed position that have a ratio of two in time scales.

The first observational period in Fig. 9, April to August 1980, does not seem to follow the usual pattern. It appears that we are looking at two distinctly different cases A and B (see Fig. 5). In case A the currents decrease to low values below mid-depth, similar to what is found during the events discussed earlier. In case B currents are strong from nearsurface to near-bottom, without much phase change 



FIG. 10. Median filtered temperature versus low-pass filtered current for uppermost series of 5 events indicated in Fig. 9. over depth, indicating a large barotropic component. A similar behavior is found in events at mooring 278 closer to the Canary Islands, but not so persistently at moorings 276 or 277 closer to the Azores (see Fig. 6 ). This suggests that barotropic motions increase their relative contribution when approaching the region of the Canary Current, closer to the continental slope. It should also be noted that during the given observational period currents closer to the Canary Islands are less energetic.

The cases $F$ and $G$ in Fig. 9 have a particular depth dependence of currents. A current maximum is found at the depth range of the Mediterranean Water (see Fig. 5), and the composite temperature time series for those levels indicate a temperature increase occurring simultaneously with the strong currents. This apparently is a large saline lens, with an increased content of Mediterranean Water, but also with a current field anomaly related to it that is observed at all depth levels in Fig. 5. Both cases have been discussed in more detail by Armi and Zenk (1984).

\section{Baroclinic current profiles and volume transport}

In this section we will compare vertical changes of velocity observed at moorings 276 and 277 to vertical current profiles observed from geopotential anomalies for station pairs close to these moorings. One has to keep in mind that mooring data give the total current while hydrographic observations only provide the baroclinic part of it, and synopticity is only approximately given in such comparisons. A strong current event with southward velocities was observed at mooring 277 in February 1982 (see Fig. 6). The hydrographic observations from F.S. Poseidon in early April 1982 indicated a current band oriented to the south just north of mooring 277 , with the largest geopotential anomaly differences here occurring between CTD stations 336 and 337 (see Fig. 1). It is reasonable to assume that in both cases we observed the same alongfront event, with the front having been somewhat displaced from February to April 1982. As already noted in the XBT data of F.S. Meteor (Fig. 3 ), a strong current event with eastward velocities is found at mooring 276 in March 1982 (event $J$ in Fig. 9), and a large geopotential anomaly difference exists between CTD stations 319 and 320 in early April 1982.

Three baroclinic current profiles from station pairs 131/144 (XBT data from Meteor, see Fig. 3) and $319 / 320$ and 336/337 (both CTD data from Poseidon, see Fig. 1) are shown in Fig. 12 with arbitrary zerolevels at 700 and $1500 \mathrm{~m}$, respectively. Also given are the mean speeds observed at mooring 277 during the above strong current events. As is apparent from Fig. 6, a zero-level can be expected for the event in 


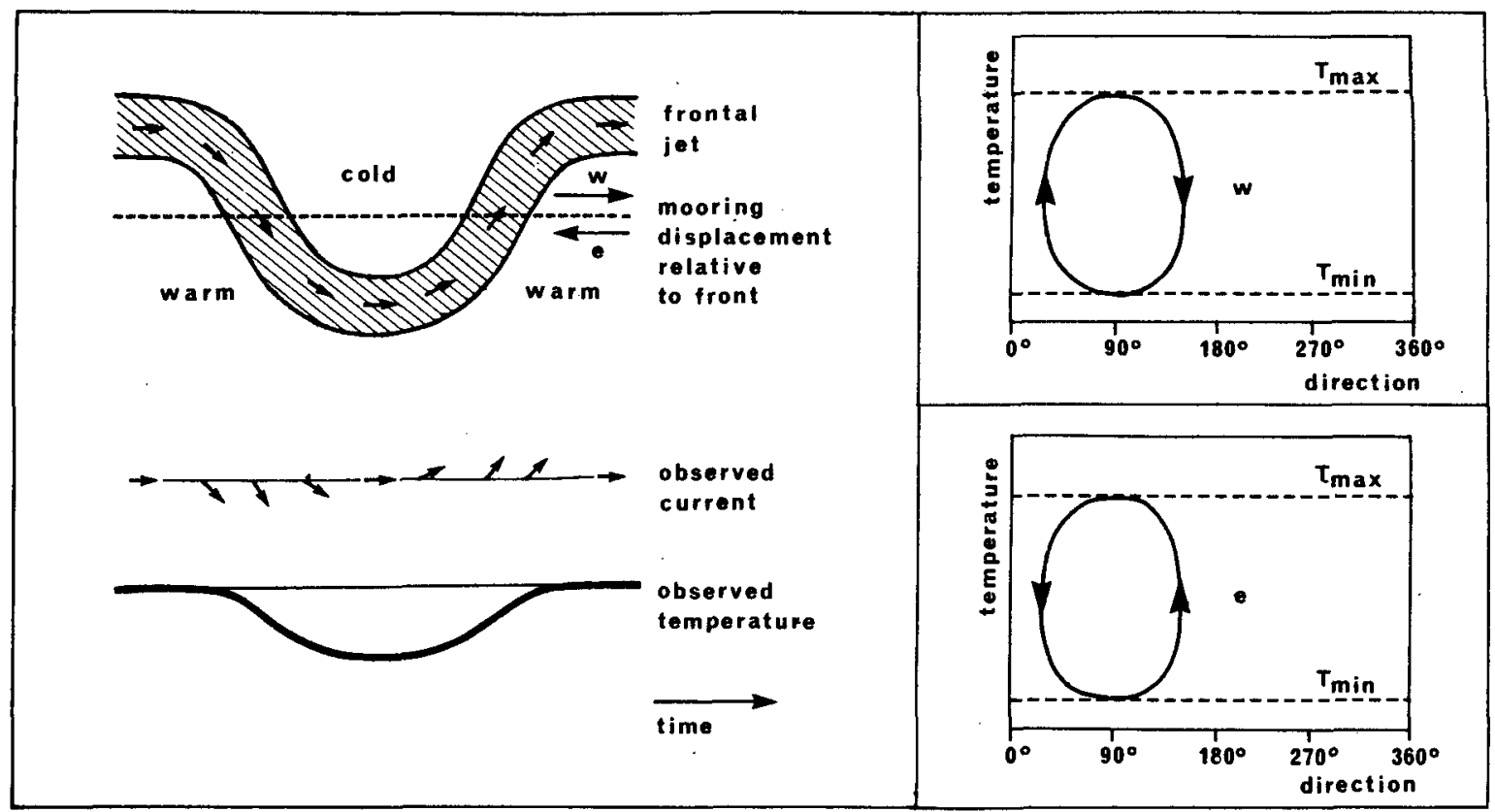

FIG. 11. Schematic meandering front and current and temperature changes corresponding to a westward (w) or eastward (e) phase propagation of the meander past the observation site and related changes of temperature versus current direction.

February 1982 somewhat below $3029 \mathrm{~m}$. (A similar result is found from Fig. 4 with a phase reversal somewhat below $3008 \mathrm{~m}$ in September 1980.) We select an arbitrary zero-level of $3200 \mathrm{~m}$ and, using least squares, fit the mean geostrophic profile (approximated by a third-order polynomial) to the mean

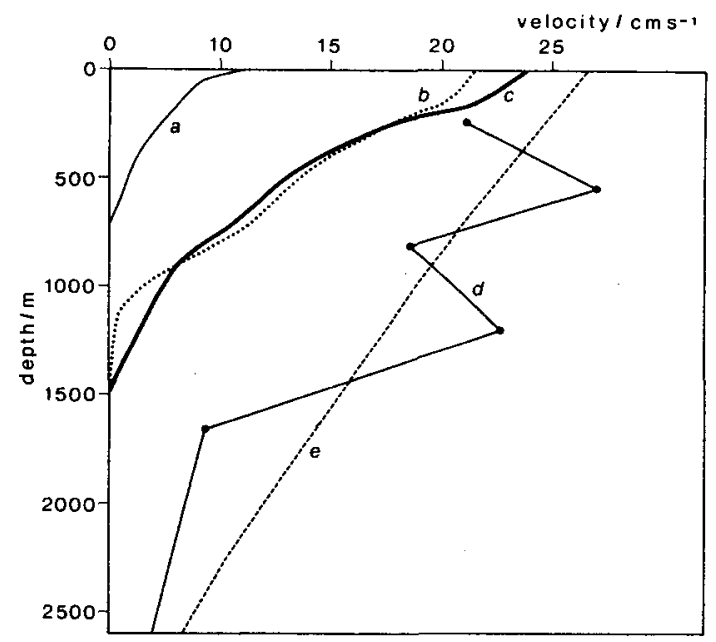

FIG. 12. Vertical profiles of baroclinic current obtained from station pairs XBT 131,144 (a) relative to $700 \mathrm{db}$ and CTD 336 , 337 (b) and CTD 319,320 (c) relative to $1500 \mathrm{db}$. Linear interpolation of 10-day mean velocity (12-22 February 1982) at mooring 277 (d) and least-square fit to these data with heavily weighted zero-value at $3200 \mathrm{~m}$ (e). For positions see Figs. 1 and 3. speed values from the moorings with a heavily weighted zero-value at $3200 \mathrm{~m}$. The resulting absolute current profile is also presented in Fig. 12. The total transport between the surface and $3200 \mathrm{~m}$, resulting from this profile with a CTD station distance of about $55 \mathrm{~km}$, is approximately $17 \times 10^{6} \mathrm{~m}^{3} \mathrm{~s}^{-1}(17$ $\mathrm{Sv})$. The various profiles, obtained from geostrophic calculations and direct observations, display a similar shape.
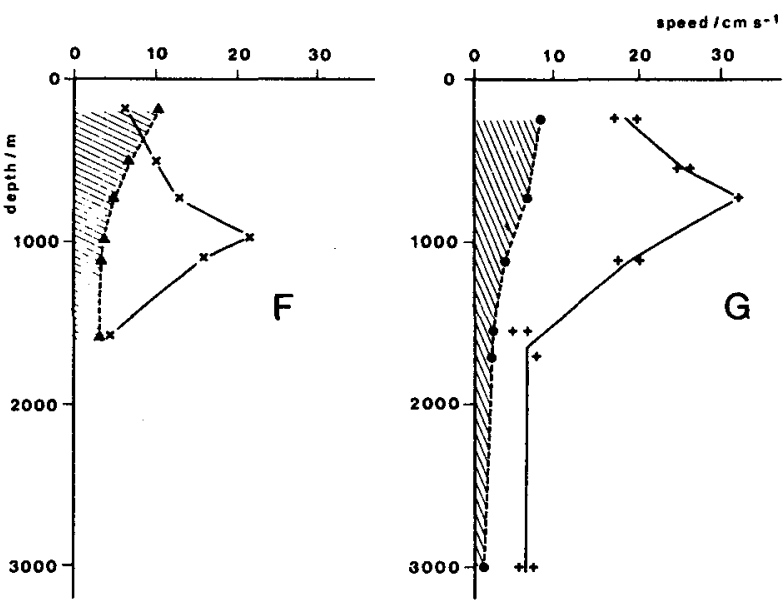

FIG. 13. Observed speeds (crosses) at mooring 276 averaged during events $F$ and $G$ (see Fig. 9) and during total observation period of the respective mooring periods (full triangles and circles) In case $G$ the high speed event consisted of two maxima, which are depicted as two crosses at the instruments' levels. 
While the current speeds decrease in most cases, this does not happen in events $F$ and $G$ (see Fig. 9). Vertical profiles of speed are plotted for these two events in Fig. 13 and compared to the time-average profile from mooring periods ii and iii (see chapter 2). The marked deviations in the depth range of the Mediterranean Water are immediately apparent. Thus these two events appear to be related to the passage of a lens of Mediterranean Water rather than a meander of the upper-layer front.

\section{Evidence for the front in historical data}

The current meter data indicated a front appearing repeatedly during several years of observations. If such a front is a persistent or at least a frequently occurring feature of the baroclinic flow field, it may be detectable in XBT observations averaged over longer time periods. All available XBT data for the region from $30-38^{\circ} \mathrm{N}, 15-25^{\circ} \mathrm{W}$ were used for this purpose, with spatial averages over $1^{\circ}$ latitude by $1^{\circ}$ longitude squares and seasonal averages for spring (March-May), summer (June-August), fall (September-November) and winter (December-February). The number of XBT drops per season is given in Fig. 14, indicating that the data coverage is not ideal for this high level of resolution, particularly in winter. Nevertheless fairly coherent fields result for all seasons. It is thus reasonable to assume that general trends are well represented in the resulting maps while smallscale features may be in error.

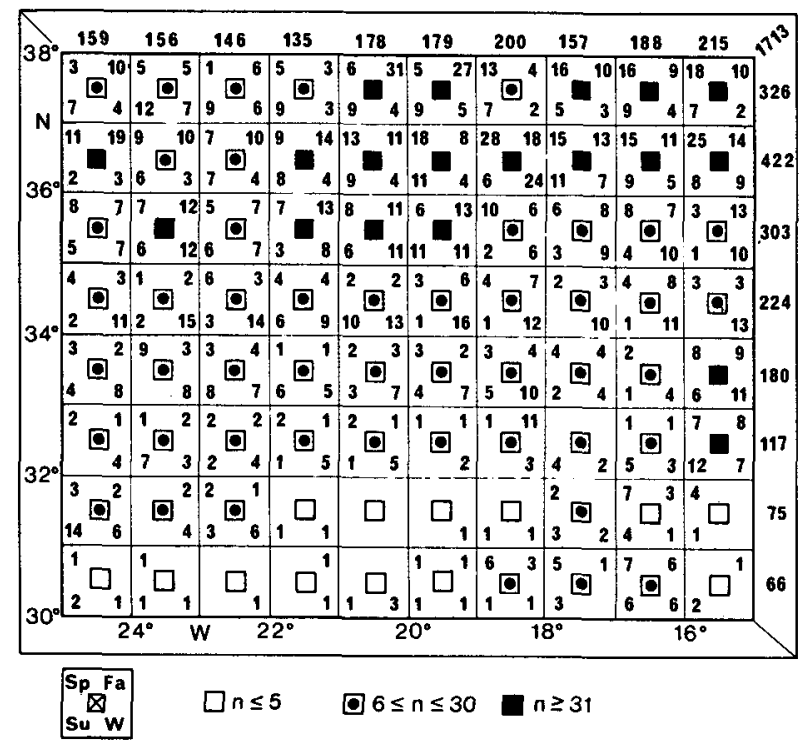

FIG. 14. Frequency distribution of historical XBT dataset. A symbol for the total number of drops in each $1^{\circ} \times 1^{\circ}$ square is given in the center, and the numbers of drops in individual seasons are given in the corners according to the pattern shown in the lower left corner of the figure.
We present $0-500 \mathrm{db}$ geopotential anomalies (dynamic heights) computed from the seasonally averaged XBT data and mean $T-S$ curves of Emery and Dewar (1982). The resulting maps (see also Fig. 1) are given in Fig. 15, with the positions of moorings 276 and 277 and Madeira Island indicated for reference. Large meridional gradients in the geopotential anomalies are found at latitudes between $33^{\circ}$ and $35^{\circ} \mathrm{N}$ in all maps, strongest in spring, weaker in summer and fall, and only occurring in the western portion of the map in winter. In the area of moorings 276 and 277 , the geopotential anomalies in spring correspond well to the front described by Käse and Siedler (1982). Particularly, the sharp southward deflection of the front at about $23^{\circ} \mathrm{W}$ in the long-term mean also appears in the spring 1982 surveys. In general, the zonal gradients in the front decrease towards the east, with the spring, summer and winter distributions indicating a branching of currents at about 23 to $19^{\circ} \mathrm{W}$. Part of the flow turns south while the remaining portion continues to the east.

It can be concluded that long-term mean distributions from XBTs, particularly the integral properties given by geopotential anomalies, indicate a front in the area to be expected during most of the year, and the mean spring pattern resembles the distribution with a meander found in spring 1982. This suggests that the subtropical front to the southeast of the Azores is a persistent or a least frequently occurring phenomenon. Given only the seasonal changes in the flow field obtained from the historical XBT data set, current meters at the above positions in the area of largest property gradients would experience major changes in current velocity. Additional meandering on shorter time scales will further increase the observed current variability.

\section{Conclusions}

The observed strong current events southeast of the Azores are mostly related to the subtropical front that had been found in recent hydrographic and satellite-tracked drifter surveys. The correlation of temperature and current direction changes obtained from mooring data during these events allows one to determine the directional propagation of frontal meanders. The front can also be seen in geopotential anomaly maps from historical XBT data, particularly in spring. Apparently the front is a persistent or quasi-persistent phenomenon in this area.

The vertical distribution of velocity during frontal passages displays a general decrease of speed with depth, but the level of no or slow motion is not found at about $1500 \mathrm{~m}$ as expected for the mean field (Stramma, 1984), but at much deeper levels. In two cases the current speed was found to be higher near the $1000 \mathrm{~m}$ level than above and below, with a 

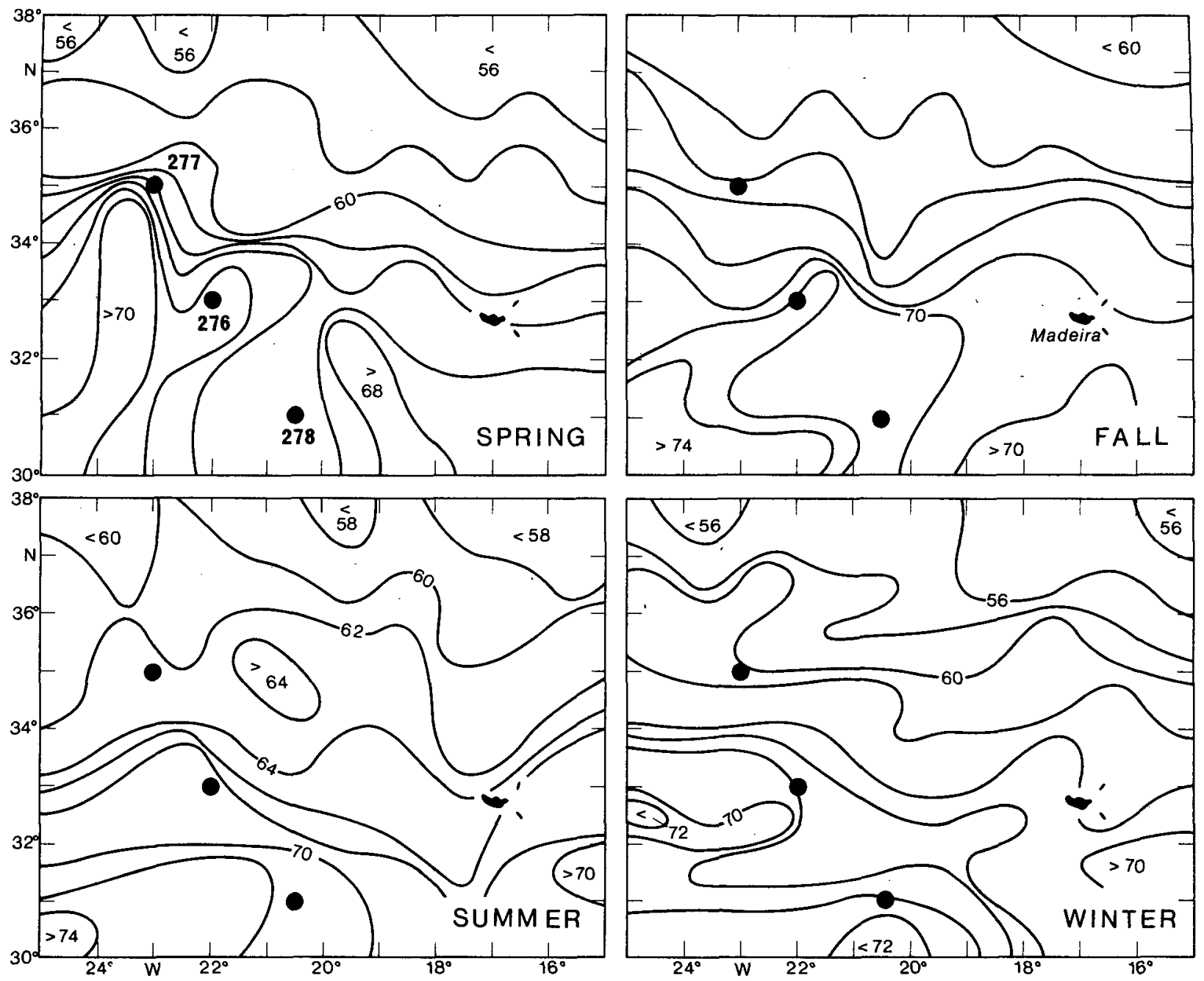

$$
\Delta D_{500} / 10^{-1} \mathrm{~m}^{2} \mathrm{~s}^{-2}
$$

FIG. 15. Geopotential anomaly relative to $500 \mathrm{db}$ for the four seasons, obtained from the historical XBT dataset using mean temperature-salinity relationships.

simultaneous increase in temperatures at this depth range. Apparently the current at that time was related to a Mediterranean Water lens.

Acknowledgments. The authors thank the staff of the Marine Physics Department and also R. H. Käse and $W$. Hiller at the Institut für Meereskunde, Kiel, Federal Republic of Germany, and the staff of the Department of Oceanography, University of British Columbia, Vancouver, Canada, for their assistance in data collection and processing. The first author was a guest investigator at the Woods Hole Oceanographic Institution, U.S.A., during the preparation of this manuscript. Appreciation is extended for the support of this institute. The study was funded by the Deutsche Forschungsgemeinschaft (DFG, SFB 133) and the Canadian Natural Sciences and Engineering Research Council (NSERC).

\section{REFERENCES}

Armi, L., and W. Zenk, 1984: Large lenses of highly saline Mediterranean Water. J. Phys. Oceanogr., 14, 1560-1576.

Bunker, A. F., 1976: Computations of surface energy flux and annual air-sea interaction cycles of the North Atlantic Ocean. Mon. Wea. Rev., 104, 1122-1140.

Dickson, R. R., 1983: Global summaries and intercomparisons: Flow statistics from long-term current meter moorings. Eddies in Marine Science, A. R. Robinson, Ed., Springer, 278-353.

Emery, W. J., 1983: On the geographical variability of the upper 
level mean and eddy fields in the North Atlantic and North Pacific. J. Phys. Oceanogr., 13, 269-291.

— depth and temperature-depth curves from the North Atlantic and the North Pacific. Progress in Oceanography. Vol. 11, Pergamon, 219-305.

Gould, W. J., 1985: Physical oceanography of the Azores Front. Progress in Oceanography, Vol. 14, Pergamon, 167-190.

Hellerman, S., and M. Rosenstein, 1983: Normal monthly wind stress over the world ocean with error estimates. $J$. Phys. Oceanogr., 13, 1093-1104.

Käse, R. H., and J. Rathlev, 1982: CTD-data from the North Canary Basin-"Poseidon" Cruise 86/2-26 March-13 April, 1982. Ber. Inst. f. Meereskunde Kiel, No. 103, 130 pp.

- and G. Siedler, 1982: Meandering of the subtropical southeast of the Azores. Nature, 300, 245-246.

-, W. Zenk, T. B. Sanford and W. Hiller, 1985: Currents, fronts and eddy fluxes in the Canary Basin. Progress in Oceanography, Vol. 14, Pergamon, 231-257.

Maillard, C., 184: Mean circulation and exchanges in the Northeastern Atlantic from historical data. Rapp. P.v. Réun. Int. Explor. Mer, 185, 131-139.
Müller, T. J., 1981: Current and temperature measurements in the North-East Atlantic during NEADS. Ber. Inst. f. Meereskunde, Kiel, No. 90, 100 pp.

_- 1984: Eulerian current measurements from the North East Atlantic, March 1982-October 1983-A Data Report. Ber. Inst. f. Meereskunde, Kiel, No. 127, 99 pp.

and XBT-sections from the North East Atlantic October 1980March 1982-A Data Report. Ber. Inst. f. Meereskunde, Kiel, No. $114,145 \mathrm{pp}$.

Pollard, R. T., and S. Pu, 1985: Structure and circulation of the upper Atlantic Ocean northeast of the Azores. Progress in Oceanography, Vol. 14, Pergamon, 443-462.

Roden, G. I., 1972: Temperature and salinity fronts at the boundaries of the subarctic-subtropical transition zone in the Western Pacific. J. Geophys. Res., 77(36), 7175-7187.

Siedler, G., and L. Stramma, 1983: The applicability of the $T / S$ method to geopotential anomaly computations in the Northeast Atlantic. Oceanol. Acta, 6(2), 167-172.

Stramma, L., 1984: Geostrophic transports in the warm water sphere of the eastern subtropical North Atlantic. J. Mar. Res., 42(3), 537-558. 